\title{
Personality Type and Experience of Domestic Violence Among Married Women in Southwest Nigeria
}

\author{
MOTUNRAYO IDIAT FASASI ${ }^{1}$ and MATTHEW AYODELE ALABI ${ }^{2 *}$
}

${ }^{1}$ Health Centre, Obafemi Awolowo University, Ile-Ife, Nigeria.

${ }^{2}$ Academy For Health Development, Ile-Ife, Nigeria.

\begin{abstract}
Worldwide, the incidence of violence regardless of the form is increasing on a daily basis. Although, both men and women are victims and perpetrators of violence, the rate of experience of violence undeniably differs according to gender, with more women bearing the larger burden of experience of violence. Yet, not much is known about the effect of personality treait on experience of domestic violence among women. This study examine the relationship between personality type and experience of domestic violence among currently married women in Southwestern Nigeria. The original survey adopted a mixed method approach involving the collection of both quantitative and qualitative data. However, analysis in this study was restricted to the quantitative data. Primary data were collected using semistructured questionnaire. A total of 400 eligible respondents were randomly selected out of the total population of 290,280 women of reproductive age. The study revealed $40 \%$ of married women in the study area experienced at least one form of violence or the other. However, verbal/emotional violence accounted for the highest prevalence rate $(60.0 \%)$, followed by physical violence $(37.0 \%)$ and sexual violence $(23.2 \%)$. Findings also revealed personality trait was a significant predictor of domestic violence among women. Women with neuroticism, agreeableness and conscientiousness personality had higher likelihood of experiencing domestic violence relative to women with the extraversion personality. The openness personality trait was not significant in predicting experience of domestic violence. The study found high prevalence of domestic violence, while verbal/emotional violence remains the most prevalent form of domestic violence experienced by the women. Personality trait of the women was a significant predictor of experience of domestic violence.
\end{abstract}

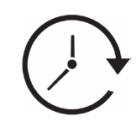

Article History

Received: 14 December 2020

Accepted: 03 January 2020

\section{Keywords}

Domestic Violence, Married Women, Personality, Trait.

CONTACT Matthew Ayodele Alabi 2 ayoalabi85@gmail.com 9 Academy for Health Development, Ile-lfe, Nigeria.

\section{(c) (i)}

(c) 2020 The Author(s). Published by Enviro Research Publishers.

This is an Open Access article licensed under a Creative Commons license: Attribution 4.0 International (CC-BY).

Doi: http://dx.doi.org/10.12944/CRJSSH.3.2.12 


\section{Introduction}

Nearly three decades ago, Domestic Violence (DV), the issue of domestic violence did not constitute an important discourse requiring international attention. During this period, one could only imagine the level of hardship and pains experienced by victims of domestic violence who have suffered in silence, with little or no attention from the public about their plight. However, things began to change in the 80s when women begin to organize themselves both locally and internationally to express their displeasure over violence against women and abuse. Similarly, available statistics showed globally, $35 \%$ of women have experienced violence by their partners in their lifetime ${ }^{1,3}$. For every five women, one has experienced sexual abuse as a child, when compared to one out of every ten men. More so, nearly 2 million women are assulated in the United States on a yearly basis by their partner, while in the United Kingdom, one quarter of women are victims of domestic violence (DV) during their lifetime ${ }^{1}$.

In Nigeria, data from the most recent Nigeria Demographic and Health Survey (2018), a nationally representative survey revealed an upward trend in the experience of domestic violence among women age 15-19 from their partners. In 2008, a national prevalence of $25 \%$ was reported, rising to $31 \%$ in 2013 and now 36\% in 20184. Sadly, due to several factors, usually embedded in culture and religion, higher proportion of women also continue to endorse the perpetration of violence from their male partner. This is evidence in the data indicating $28 \%$ of women in the country endorse wife beating by her partner under certain conditions such as denying her partner sex, neglecting the children among others.

No doubt, the silient attitude of women, influenced by the patriarchy nature of Nigeria, further exacerbates the woes of these women. In 2016, there was a case of verbal abuse against a female Senator of the Federal Republic of Nigeria by her colleague in the Senate which generated several outburst and condemnation among members of the public and was widely published in the social media ${ }^{5}$. Three years after the incident, another male Senator of the Federal Republic of Nigeria was caught on camera physically assaulting a woman at a sex toy shop, which, as usual also generated wide outcry and condemnation on social media and from the public.
Sadly, despite report indicating that a court slammed a fine of N50 million naira against the said Senator, that was all that was know about his charge ${ }^{5}$. Notwithstanding, several cases of both reported and unreported incidence of violence no doubt occur without the victims getting appropriate justice.

Furthermore, women are genrally considered more susceptible to domestic violence in settings where violence in several instances are considered a socially accepted norms6, while men have over and over again, been known to coming up with countless motives behind their unacceptable actions against their partners, by subjecting women to all forms of violence, ranging from physical, economical, psychosocial, emotional, and sexual violence ${ }^{7}$.

Vast number of studies have been conducted on domestic violence ${ }^{8-16}$. However, most of these studies have focused on demographic, socio-economic, household and cultural characteristics of the victims $^{17-19}$, while literature relating experience of domestic violence to personality type has been sparsely explored especially among women in Nigeria despite the high rate of domestic violence prevalent in the country. This notwithstanding studies, which have linked personality trait with attitude towards and experience of domestic violence. Personality is defined as set of expected behaviour and emotional patterns resulting from biological and environmental factors ${ }^{20}$.

Empirical studies have documented evidence suggesting personality trait such as the Big Five trait to be a significant predictor of attitude towards and experience of violence ${ }^{21-24}$. For instance, previous study has found people with neuroticism personality trait to exhibit reactive and aggressive behaviour ${ }^{25}$. On the other hand, people with the agreeableness personality are found to exhibit behaviour that makes them tolerant, supportive, and non-violent in romantic and marital relationships ${ }^{26}$. However, despite evidence linking personality trait with attitude towards and experience of violence, research along this line seems sparse in Nigeria. This study, therefore, seeks to bridge this knowledge gap and contributing to the body of literature on the effect of personality type on the experience of domestic violence among women in Southwest Nigeria. 


\section{Materials and Methods Study Population and Sampling Technique}

The study was conducted in three out of the six states that constitute the South-west region of Nigeria. The three states selected in this study are: Abeokuta (Ogun state), Akure (Ondo state), and Ibadan (Oyo state). The states were selected based on their diverse populations allowed beter comparisions in terms of cultural, religious characteristics, and their effects on the attitudes of women towards domestic violence. The areas have also been reported to have one of the highest prevalence rate of domestic violence in the region according to report from the Nigeria Demographic and Health Survey ${ }^{4}$. The population for the study consist of all women of reproductive age (15-49 years) residing in the South-western of the country and drawn from the selected states. The sample size was 400 women of reproductive age drawn from these three states. In each state, one major local government district where women of reproductive age in appreciable numbers was selected. The population for each local government was drawn from the 2006 National Population Census Reports and projected up to 2016.

\section{Research Instrument}

Data was collected using semi-structed questionnaire. Before the main field administration, a pilot study was conducted among 50 women located outside the study area. Pilot study was conducted to ascertain the validity and reliability of the instrument. The Cronbach alpha test was used to determine the reliability of the instrument. The Cronbach alpha coefficient value obtained was 0.876 . The final instrument was validated by two experts from the Department of Psychology, Obafemi Awolowo University, Ile-Ife. Experience of domestic violence was assessed using series of questions to ascertain the level of experience of at least one form of violence - physical, verbal/emotional, and sexual violence. Questions on experience of any of the violence was dichotomized with yes as 1 indicating experience of a particular violence and no as 0 , indicating non experience of a particular violence. Prevalence of any form of violence was measured as often, occasional, never, and more than 12 months preceding the survey.

\section{Data Collection Procedure/Ethical Clearance}

Ethical approval for this study was obtained from the appropriate authority - the Institute of Public Health Ethical Committee of Obafemi Awolowo University, Ile-Ife, Nigeria. Consent to participate in the study was also sought from the respondents. The participants were briefed about the objeive of the study and were also informed of their right to withdraw from the study at any point during the interview without any penalty. Also, they were assured about the confidentiality and anonymity of information provided. The researcher and the trained research assistants visited each of the selected areas for the purpose of data collection.

\section{Measurement of Outcome Variable}

The outcome variable for this study is domestic violence (DV). This was was measured in three levels namely: physical, emotional, and sexual. Each of the category of DV was dichotomized and coded as 1 if experienced a particular type of violence, otherwise coded as 0 as not experienced. The main predictor variable is the personality type. Personality type was measured using brief version of the Big Five Personality Inventory (BVBFPI), developed by Rammstedt and John (2007) and adopted to provide an inventory of personality for research purpose. It is a 10-item version of the Big Five Inventory. The scale seeks to provide standards for the total sample and sub-sample using data from a larger sample representative of the population subject to different socio-demographic effects, age and leve of education on the Big Five Inventory (BFI)-10. The five personality type are: Extraversion: 1R, 5; Agreeableness: 2, 7R; Conscientiousness: 3R, 8; Neuroticism: 4F, 9 and Openness to Experience: $5 \mathrm{R}, 10$. The reliability analysis using Cronbach Alpha coefficient yielded a value of $\alpha=0.70$ for the personality $\alpha=0.77$ for attitude towards violence.

\section{Data Analysis}

Data analysis involved performing both descriptive and inferential analysis. Descriptive analysis performed include frequency counts and percentages, while inferential analysis involved performaing Binary logistic Regression Analysis. The Odds ratio were reported. All analysis were 
performed using Statistical Product Service Solution (IBM-SPSS) version 20.0 software. In all statistical comparisons, responses were considered significant at $\mathrm{P}<0.05$.

\section{Results}

\section{Socio-demographic Characteristics}

The result of the background characteristics of respondents revealed participants in the age group 25-29 accounted for the highest proportion (29.2\%), followed by respondents in the age group 35-39 years (19.2\%) and $30-34$ years (19.0\%). Nearly three quarter $(72.2 \%)$ of the respondents practiced Christianity, while more than half $(55.2 \%)$ had higher education, with a small number $(4.0 \%)$ having no education. Significant proportion (77\%) of women earned less than N50, 000 as monthly income and $(80.2 \%)$ were from the monogamous family type.
The low income level reported among the women suggest majority of the women are characteriszed with low socio-economic status despite more than half reporting having higher education. With respect to personality trait, nearly half $(46.3 \%)$ had the extraversion personality trait, followed by openness (19.3\%), conscientiousness (15.5\%), neuroticism (10.5\%), and agreeableness (8.5\%).

\section{Pattern of Domestic Violence}

The prevalence of at least one form of domestic violence: physical, sexual, and verbal/emotional in this study was quite high. The pattern indicates verbal/emotional violence was the most commonly perpetrated form of domestic violence against women $(60.0 \%)$, followed by physical $(37.0 \%)$, and sexual $(23.2 \%)$ violence.

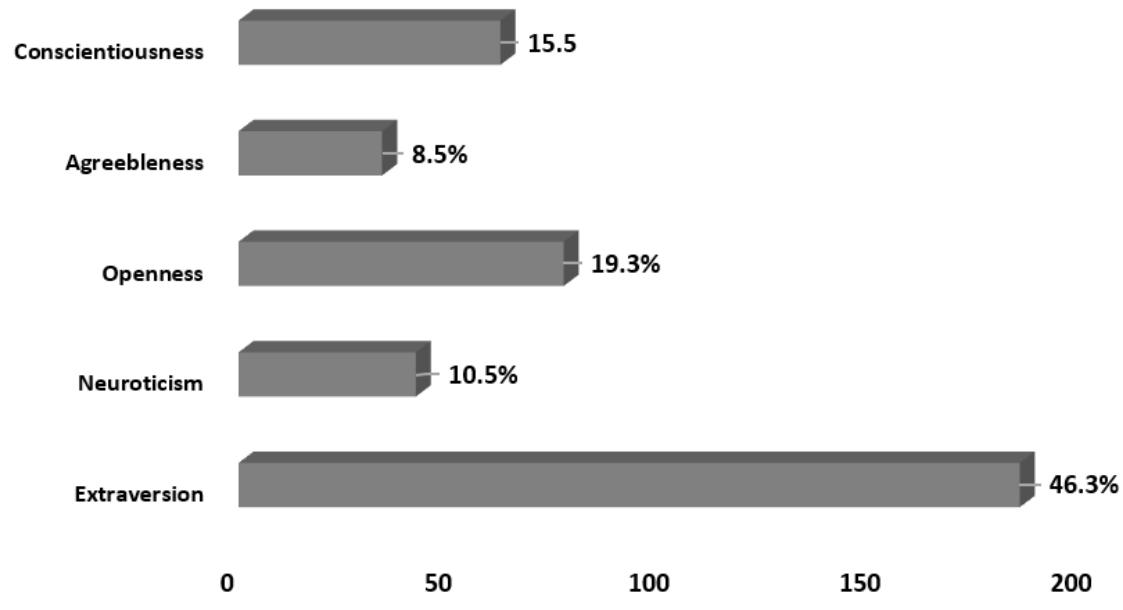

Fig. 1: Disttribution of respondents according to personality type

Relationship between Personality Type and Incidence of Domestic Violence

Findings from this study showed that personality trait was a significant predictor of the incidence of domestic violence among women. With respect to specific personality type, women with neuroticism, agreeableness, and conscientiousness personality trait demonstrated higher likelihood of experiencing domestic violence relative to women with the extraeversion personality trait. For instance, women with neuroticism personality demonstrated 2.5 times higher odds of experiencing domestic violence $(O R=2.50, p<0.05)$ relative to women with the extraversion personality. Also, women with agreeableness $(\mathrm{OR}=2.63, \mathrm{p}<0.05)$ and conscientiousness personality $(\mathrm{OR}=2.14, \mathrm{p}<0.05)$ were 2.63 and 2.14 times more likely to experience domestic violence relative to women with the extraversion personality (Figure 1).

\section{Discussion and Conclusion}

Domestic violence against women continues to show upward trend in Nigeria. This upward trend however, suggest government and relevant stakeholders are not doing enough to check this callous act against women in the country. This is in addition to poor data, as most of the domestic violence occuring in the country goes unreported, couple with deep cultural 
and religious factors that have shape and determine response towards the perpetrators and the victims. Findings from this study revealed that nearly two thirds of women in the study area had experienced at least one form of violence or another. However, verbal/emotional violence accounted for the highest prevalence, followed by physical and sexual violence, respectively.

Table 1: Personality type and incidence of domestic violence among women

\begin{tabular}{|c|c|c|c|c|c|}
\hline $\begin{array}{l}\text { Experience of } \\
\text { domestic } \\
\text { violence }\end{array}$ & Odds Ratio & Std. Err. & $\mathbf{P}>\mathbf{Z}$ & \multicolumn{2}{|c|}{$\begin{array}{l}95 \% \text { Confidence } \\
\text { Interval }\end{array}$} \\
\hline \multicolumn{6}{|l|}{ Personality Type } \\
\hline Neuroticism & 2.5000 & 1.0119 & 0.02 & 1.1308 & 5.5269 \\
\hline Openness & 0.9588 & 0.2641 & 0.88 & 0.5588 & 1.6452 \\
\hline Agreeableness & 2.6299 & 1.1829 & 0.03 & 1.0891 & 6.3504 \\
\hline Conscientiousness & 2.1364 & 0.7097 & 0.02 & 1.1140 & 4.0969 \\
\hline Statistics & & \multicolumn{4}{|c|}{ LR chi2 (4)=14.27, $p=0.01, R^{2}=0.028$} \\
\hline
\end{tabular}

The high prevalence rate of deomestic violence have been reported in previous studies. In a cross sectional studyto examine the incidence of domestic violence against Indian women ${ }^{10}$, the authors found a wide variation in the prevalence rate across region with rates ranging from $16 \%$ to $56 \%{ }^{10}$. Another study ${ }^{11}$ among women in Benin, South-south, Nigeria, revealed a prevalence rate of $35.5 \%$, while a study on women experience and men's perspectives with respect to intimate partner violence in Ile-Ife, Osun, Nigeria ${ }^{31}$ revealed a prevalence rate of (19.9\%). Another similar study ${ }^{32}$ reported a prevalence of violence (16.3\%) among women in Osun state.

With respect to the most prevalent type of domestic violence, similar findings from a study ${ }^{28}$ among women of reproductive age in southwest Nigeria reported verbal/psychological violence as the most prevalent form of domestic violence, while sexual violence was the least common form of domestic violence women experienced in those studies. Other similar studies ${ }^{29-30}$ have reported that one third of the women were victims of at least one form of domestic violence with emotional violence as the most prevalent form of violence experienced by more than two thirds of the women, while among the married women, the immediate partner was the main perpetrator of domestic violence.
This study also revealed personality trait significantly predicted the experience of domestic violence among the women. Women with neuroticism, agree ableness, and conscientiousness personality had higher likelihood of experiencing domestic violence relative to women with the extraversion personality. This findings is consistent with previous studies $^{21,22,26,23,24}$ which have linked personality trait with attitude and experience of violence from their partners.

In clonclusion, our study revealed that incidence of domestic violence in the studied areas was quite high. Emotional violence was the most common type of domestic violence experienced, while sexual violence was the least experienced form of domestic violence among the women. This study therefore, concluded that personality traint was a significant predictor of experience of domestic violence among the women.

\section{Acknowledgement}

The authors wish to thank all the study participants for their cooperation in ensuring the success of the study. The authors also thank the two experts from the Department of Psychology, Obafemi Awolowo University, Ile-Ife, for reviewing the research iunstrument used for data collection. 


\section{Funding}

The authors received no financial support for the research, authorship, and/or publication of this article.

\section{Conflict of Interest}

The authors declare no conflict of interest.

\section{References}

1. World Health Organization (2013). Fact Sheet. Intimate Partner and Sexual Violence against Women. No.239. Updated October, 2013.

2. Tong, D. (2009). Falsely accused of Domestic Violence. NewsWithViews.com. September 17, 2009.

3. United Nations (2016). Violence against Women Factsheets. Engaging men to prevent violence against women, http://www.un.org.

4. National Population Commission (NPC) [Nigeria] and ICF (2019). Nigeria Demographic and Health Survey 2018 Key Indicators Report. Abuja, Nigeria, and Rockville, Maryland, USA: NPC and ICF.

5. Vanguard News (2016). https://www. vanguardngr.com/2019/07/sex-toy-shopassault-senators-oluremi-tinubu-abbo-inheated-argument/.

6. Jewkes, R. (2002). "Intimate partner violence: Causes and prevention". The Lancet; 359(9315): 1423-1429.

7. Oyediran, K.A. \& Isiugo-Abanihe, U. (2005). Perceptions of Nigerian women on domestic violence: evidence from 2003 Nigerian Demographic and Health Survey. African Journal of Reproductive Health; 9(2): 38-53.

8. Akpede, D. (2012). Wife-battering and Nigerian Women. Premium Times.

9. Absiubong, F., Abasiattai A.M., Bassey E.A. \& Ogunsemi O.O. (2010). Demographic Risk Factors in Domestic Violence among Pregnant Women in Uyo, a Community in the Niger Delta Region, Nigeria. Health Care for Women International, 31:10, 891-901, DOI: 10.1080/07399332.2010.486882.

10. Babu, B.V., \& Kar, S. K. (2009). Domestic violence against women in eastern India: a population-based study on prevalence and related issues. BMC Public Health, 9(1), 129.

11. Ezechi, O., Gab-Okafor C, Onwujekwe D., Adu R., Amadi E. \& Herbertson E. (2009): Intimate partner violence and correlates in pregnant HIV positive Nigerians. Arch
Gynecol Obstet 2009, 280:745-752.

12. Adegoke, T.G. \& Oladeji, D. (2008). Community norms and cultural attitudes and beliefs factors influencing violence against women of reproductive age in Nigeria. European Journal of Scientific Research, 20:265-273.

13. Adewale, R. (2007). Violence in the Family. A Preliminary Investigation and Overview of Wife Beating in Africa. Journal of International Women's Study. 19: 234-251.

14. Stark, E. (2007). Coercive Control: The Entrapment of Women in Personal Life. New York: Oxford University Press; 2007.

15. Kishor, S. \& Gupta, K. (2004). Women's empowerment in India and its States: Evidence from NFHS. Economic and Political Weekly, 39(7), 694-712.

16. Okembgo, C.N. Omideyi, A.K. \& Odomegwu, C.O. (2002). Prevalence, Pattern and Correlates of Domestic Violence in selected Igbo Communities in Imo State, Nigeria. African Journal of Reproductive Health; 6(2): 101-114.

17. Gbolahan, O.A. (2013). Socio-cultural factors influencing gender-based violence on agricultural livelihood activities of rural household in Ogun State. International Journal of Biodiversity and Conservation; 5(1) pp 1-14.

18. Oladeji, D. (2013). Personal, Situational and Socio-cultural factor as correlates of intimate partner abuse in Nigeria. Advancement in Sexual Medicine. Journal of Social Science; 3(4): 92-97.

19. Olawale, D. \& Adegoke, T.G. (2008). Personal, Situational and Socio-cultural factors as correlates of intimate partner abuse in Nigeria. Journal of Social Science; 16(1): 57-62.

20. Corr, P.J. \& Matthews G. (2009). The Cambridge Handbook of Personality Psychology (1. Published ed.). Cambridge, U.K.. Cambridge University Press. 
21. Oguntayo, R., Oyeleke, J.T., John-Oguntayo, O., \& Aajayi-Hutchful, F.A. (2020). Personality Traits, Emotional Intelligence, Sociocontextual Factors and Spousal Violence: The Trajectory of COVID-19 Pandemic Lockdown. International Journal of Behavioral Sciences, 14(2), 101-107.

22. Motevaliyan, S.M., Yaacob, S.N., Juhari, R., Mansor, M., \& Baratvand, M. (2014). Personality traits and severity of wife abuse among Iranian Women. Asian Social Science, 10(7), 234.

23. Sharma, L.A. (2011). Personality and intimate partner aggression in Gorakhpur, Uttar Pradesh, India.

24. Sullivan, M., Senturia, K., Negash, T., ShiuThornton, S., \& Giday, B. (2005). "For Us It Is Like Living in the Dark" Ethiopian Women's Experiences With Domestic Violence. Journal of interpersonal violence, 20(8), 922-940.

25. Bernerth, J.B., Armenakis, A.A., Feild, H.S., Giles, W. F., \& Walker, H. J. (2008). The influence of personality differences between subordinates and supervisors on perceptions of LMX: An empirical investigation. Group \& Organization Management, 33(2), 216-240.

26. Pobutsky, A., Brown, M., Nakao, L., \& ReyesSalvail, F. (2014). Results from the Hawaii domestic violence fatality review, 2000-2009. Journal of injury and violence research, 6(2),
79.

27. Rammstedt, B. \& John, O.P. (2007). Big Five Inventory-10 (BF-10). Measuring Personality in one minute or less. ; Journal of Research in Personality, 41, 203-212. Retrieved 31-72010 on http://www.ocf.berkeley.edu.

28. Okenwa, L.E., Lawoko S. \& Jansson B. (2009). Exposure to Intimate Partner Violence amongst Women of Reproductive Age in Lagos, Nigeria: Prevalence and Predictors. $J$ Fam Viol (2009) 24:517-530.

29. Ashimi, A.O.\& Amole T. G. (2015). Prevalence and predictors for domestic violence among pregnant women in a rural community Northwest, Nigeria. Niger Med J 2015;56: 118-21.

30. Adesina, O., Oyugbo I. \& Oladokun A. (2011). Prevalence and pattern of violence in pregnancy in Ibadan, South-West Nigeria. J Obstet Gynaecol;31:232-6.

31. Fatusi, A.O \& Alatise, I.O. (2006). Intimate partner violence in Ile-Ife, Nigeria. Women's experience and men's perspective. Gender Behaviour; 4(2): 764-781.

32. Fasasi, M.I. (2014). Influence of Spousal Violence on the Psychological Well-being of Married Women in Osun State. M.Sc. Thesis submitted to the Department of Psychology, Faculty of Social Sciences, Obafemi Awolowo University, Ile-Ife. Osun State. Nigeria.

\section{Appendix I}

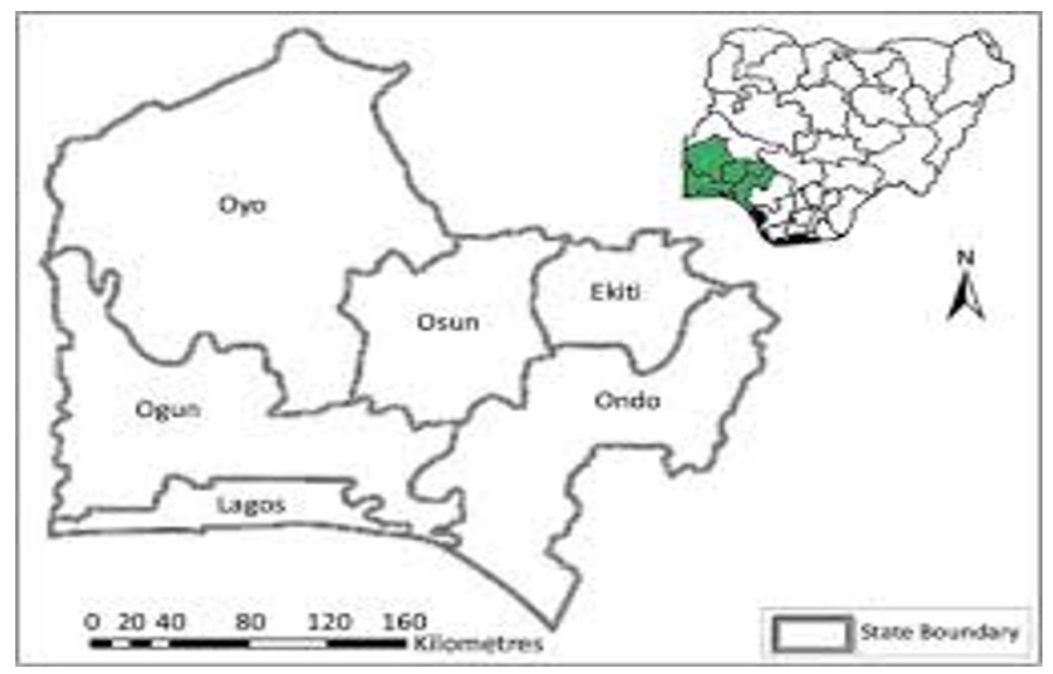

Fig. 2: Map of Southwest Nigeria Showing the study areas 